\title{
Syntheses and Properties of Periodic Copolymers
}

\author{
Kenji YoKota, Takanori Kougo, and Tadamichi HIRABAYASHI \\ Materials Research Laboratory, Nagoya Institute of Technology, \\ Gokiso-cho, Showa-ku, Nagoya 466, Japan
}

(Received November 9, 1982)

\begin{abstract}
A}_{2}$ B-type periodic copolymers with the structure, $\mathrm{fCH}_{2} \mathrm{CH}_{2}-\mathrm{CH}_{2} \mathrm{CH}_{2}-$ $\left.\mathrm{CH}_{2} \mathrm{CXY}\right\}$ were synthesized by hydrogenating various alternating butadiene-acrylic copolymers. Substituents X, Y were $\mathrm{Cl}, \mathrm{COOCH}_{3} ; \mathrm{H}, \mathrm{COOCH}_{3} ; \mathrm{CH}_{3}, \mathrm{COOC}_{2} \mathrm{H}_{5} ; \mathrm{CH}_{3}, \mathrm{COOCH}\left(\mathrm{CH}_{3}\right)_{2} ; \mathrm{CH}_{3}$, $\mathrm{COOC}_{6} \mathrm{H}_{5} ; \mathrm{CH}_{3}, \mathrm{COOCH}_{2} \mathrm{C}_{6} \mathrm{H}_{5}$; and $\mathrm{H}, \mathrm{CN}$. Identification of the structure and tensile properties of the copolymers are described. A periodic copolymer was compared with a random copolymer of the same composition. The periodic copolymer showed crystalline melting and higher glasstransition temperatures and was a harder and less extensible material than the random copolymer.

KEY WORDS Periodic Copolymer / Butadiene / Ethylene / Acrylic

Monomer / Hydrogenation / Tensile Properties / Sequence Regularity /
\end{abstract}

Numerous investigations on the syntheses and properties of alternating copolymers (AB-type periodic copolymers) have been published. ${ }^{1-3}$ Some of these discuss the properties of the copolymers in comparison with those of random copolymers.

However, little is known in regard to periodic copolymers with regularly repeating three or more monomer units. Hsieh ${ }^{4}$ obtained ABC-type copolymers by heating ethylene oxide, succinic anhydride and a large excess of tetrahydrofuran in the presence of an aluminum triisobutyl catalyst.

$$
\begin{aligned}
& \mathrm{CH}_{2} \mathrm{CH}_{2}+\mathrm{CH}_{2} \mathrm{CH}_{2}+\mathrm{CH}_{2} \mathrm{CH}_{2}
\end{aligned}
$$

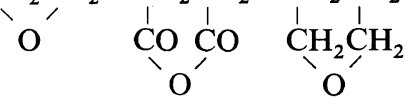

$$
\begin{aligned}
& \longrightarrow+\mathrm{CH}_{2} \mathrm{CH}_{2} \mathrm{O}-\mathrm{COCH}_{2} \mathrm{CH}_{2} \mathrm{COO}- \\
& \mathrm{CH}_{2} \mathrm{CH}_{2} \mathrm{CH}_{2} \mathrm{CH}_{2} \mathrm{O}+
\end{aligned}
$$

Evidence for the proposed structure does not seem convincing and the intrinsic viscosities of the copolymers were low. Saegusa and coworkers ${ }^{5}$ reported several $\mathrm{ABC}$ - and $\mathrm{A}_{2} \mathrm{~B}$-type copolymers by spontaneous copolymerization via the zwitter-ion mechanism of monomers, e.g. ethylene phenylphosphonite, methyl acrylate and carbon dioxide to the copolymer.<smiles>CCCP(=O)(CCC(C(=O)O)c1ccccc1)C(=O)O</smiles>

Evidence was obtained for the structure by elemental analysis, IR and NMR spectra, and alkaline hydrolysis. Here again, however, the molecular weight of the copolymer was low.

In our previous papers ${ }^{6,7}$ we reported the hydrogenation of an alternating butadiene-methyl methacrylate (MMA) copolymer and the properties of the product copolymer.

$$
\begin{aligned}
& \underset{-\mathrm{CH}_{2} \mathrm{CH}=\mathrm{CHCH}_{2}-\mathrm{CH}_{2} \underset{!}{\mathrm{C}}+\mathrm{COOCH}_{3}}{\mathrm{CH}_{3}} \\
& \stackrel{2 \mathrm{H}}{\longrightarrow}+\mathrm{CH}_{2} \mathrm{CH}_{2}-\mathrm{CH}_{2} \mathrm{CH}_{2}-\mathrm{CH}_{2} \stackrel{\underset{1}{\mathrm{C}}+\mathrm{H}_{3}}{\mathrm{C}} \\
& \mathrm{COOCH}_{3}
\end{aligned}
$$

The product copolymer was considered to be an $\mathrm{A}_{2} \mathrm{~B}$-type periodic copolymer with regularly repeating ethylene-ethylene-MMA sequences. It was a partially crystalline, soft and tough material of high molecular weight, resembling low density polyethylene in tensile and thermal stability, but polyMMA in solubility.

In the present paper, we report the syntheses and properties of some periodic copolymers of this type. The properties of the resulting copolymers were found to vary according to the kind of acrylic monomers used. 


\section{EXPERIMENTAL}

Butadiene, methyl acrylate and acrylonitrile were commercially available extra pure reagents. Ethyl, isopropyl, phenyl, and benzyl methacrylates and methyl $\alpha$-chloroacrylate (MCA) were prepared as described before. ${ }^{8,9}$

Other reagents, the copolymerization procedure, and the characterization method for copolymers were the same as in the previous paper. ${ }^{7}$

Hydrogenation of unsaturated copolymers was carried out catalytically with atmospheric hydrogen as described in the previous paper. Some unsaturated copolymers, which were sluggish or unreactive by the above method, were hydrogenated by heating with $p$-toluenesulfonylhydrazide ${ }^{10}$ in toluene at $120^{\circ} \mathrm{C}$. Usually, the unsaturated copolymers had to be reacted twice with 2 equivalents of $p$-toluenesulfonylhydrazide for complete hydrogenation.

\section{RESULTS AND DISCUSSION}

Syntheses of Various Ethylene-Ethylene-Acrylic Copolymers

Ethylene-ethylene-MCA copolymer was easily obtained by the catalytic hydrogenation of alternating butadiene-MCA copolymer as in the case of the ethylene-ethylene-MMA copolymer. The alternat- ing copolymerization of butadiene and MCA proceeded more vigorously than the copolymerization of butadiene and MMA and took place while the frozen reactants were being warmed gradually from $-78^{\circ}$ to $0^{\circ} \mathrm{C}$ in the presence of MCA crystals.

Ethylene-ethylene--methacrylate copolymers, whose ester groups are ethyl, isopropyl, phenyl and benzyl, were synthesized and identified in the same manner as the ethylene-ethylene-MMA copolymer. Catalytic hydrogenation was sluggish or difficult for these copolymers; the alternative $p$-toluenesulfonylhydrazide method gave better results.

Ethylene-ethylene-methyl acrylate copolymer was also synthesized from butadiene and methyl acrylate. Catalytic hydrogenation proceeded smoothly.

The ethylene-ethylene-acrylonitrile copolymer could not be obtained by the catalytic hydrogenation of the alternating butadiene-acrylonitrile copolymer though attempted under various conditions. When the copolymer was heated with $p$ toluenesulfonylhydrazide, hydrogenation took place but the product became insoluble during repeated reprecipitations. Only a small portion of the product could be extracted from the insoluble product with hot deuterochloroform and showed ${ }^{13} \mathrm{C}$ NMR chemical shifts at 25.0, 26.7, 29.7, 30.7 and $120.2 \mathrm{ppm}$ from hexamethyldisiloxane.

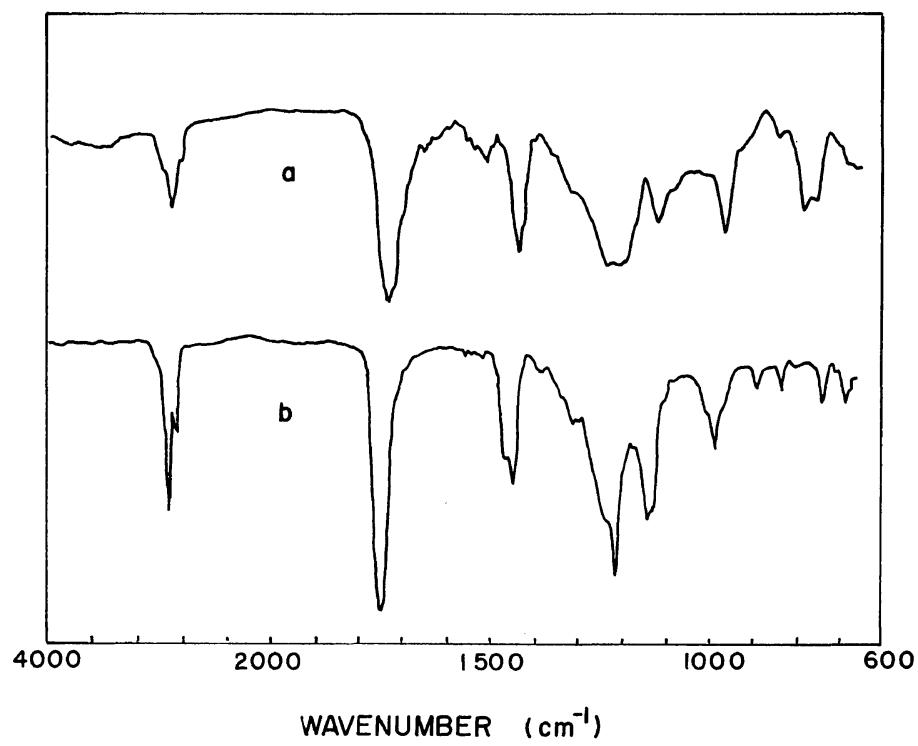

Figure 1. IR spectra of (a) the alternating butadiene-MCA copolymer before hydrogenation and (b) the periodic ethylene-ethylene-MCA copolymer following hydrogenation. 
Identification of the Copolymer Structure

As in previous papers on the MMA copolymer, all the copolymers in the present paper could be identified as having the proposed structure. The identification of the MCA copolymer is given below as a representative example.

Figures 1 and 2 show the IR and ${ }^{1} \mathrm{H}$ NMR spectra of the MCA copolymer before and after hydrogenation. The spectra before hydrogenation demonstrate that the unsaturated copolymer contains butadiene and MCA units in a 1:1 molar ratio, that successive sequences of butadiene or MCA units are absent, and that butadiene units are of the 1,4-trans structure. After hydrogenation, absorptions due to carbon-carbon double bonds disappeared both in the IR $\left(v_{=\mathrm{C}-\mathrm{H}}=3020 \mathrm{~cm}^{-1}\right.$, $v_{-\mathrm{C}=\mathrm{C}-}=1660 \mathrm{~cm}^{-1}$, and $\left.\delta_{=\mathrm{C}-\mathrm{H}}=970 \mathrm{~cm}^{-1}\right)$ and ${ }^{1} \mathrm{H}$ NMR $(-\mathrm{CH}=\mathrm{CH}-$ at $5.48 \mathrm{ppm})$ spectra. Changes due to newly formed methylene groups were observed; especially in NMR, two methylene absorptions at 2.65 and $2.08 \mathrm{ppm}$ shifted to 1.97 and $1.43 \mathrm{ppm}$ by hydrogenation. The compositions of butadiene-MCA copolymers obtained with ethylaluminum sesquichloride and vanadyl chloride at $0^{\circ} \mathrm{C}$ as determined by elemental analyses and NMR peak areas are all 1:1 molar ratios of

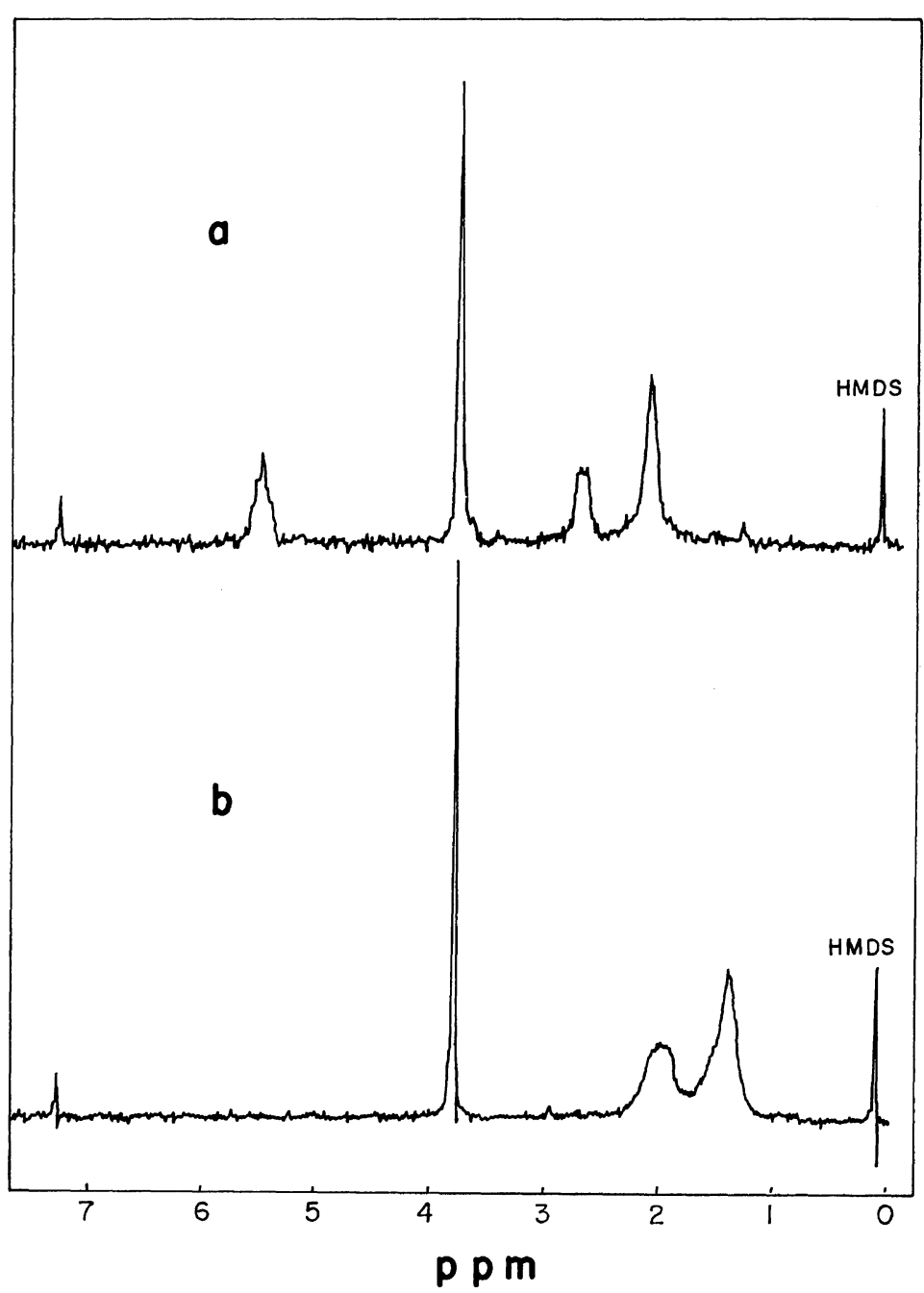

Figure 2. ${ }^{1} \mathrm{H}$ NMR spectra of (a) the alternating butadiene-MCA copolymer before hydrogenation and (b) the periodic ethylene-ethylene-MCA copolymer after hydrogenation, as recorded at $60 \mathrm{MHz}$ in $\mathrm{CDCl}_{3}$. 


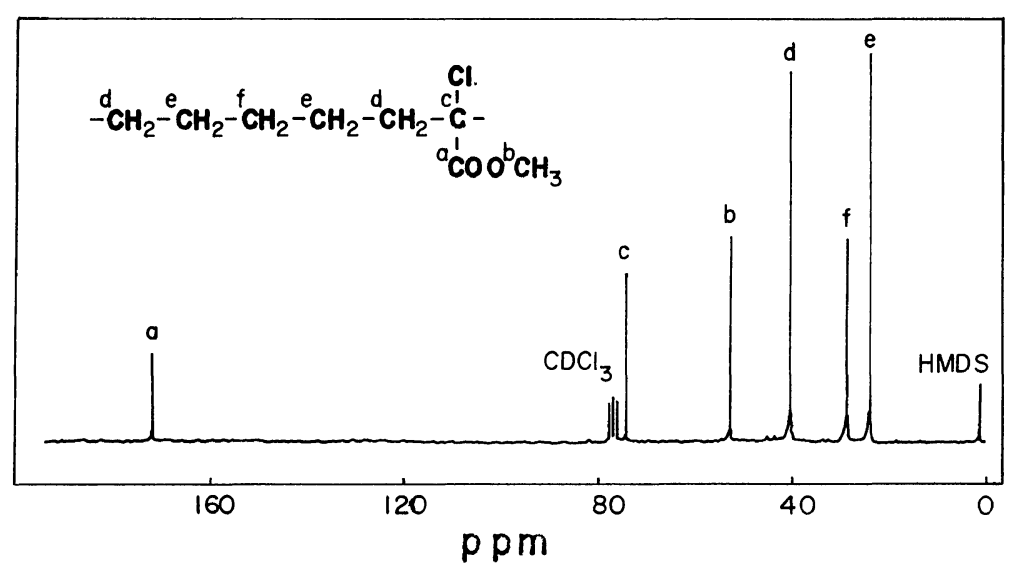

Figure 3. ${ }^{13} \mathrm{C}$ NMR spectrum of the periodic ethylene-ethylene-MCA copolymer, as recorded at $50 \mathrm{MHz}$ in $\mathrm{CDCl}_{3}$.

monomers regardless of monomer feed composition. This constitutes basic evidence for the alternating structure of the unsaturated copolymer. Thus, the hydrogenation of alternating butadiene-MCA copolymer should naturally give rise to regularly repeating ethylene-ethylene-MCA sequences.

The best and most conclusive evidence for the structure of the hydrogenated copolymer is given by the ${ }^{13} \mathrm{C}$ NMR spectrum in Figure 3 which shows only six carbon peaks in spite of eight carbons in one repeating sequence. This is because of the symmetry of the structure about the chlorinesubstituted carbon atom of the MCA unit. Peak assignments were carried out by a proton offresonance spectrum. In addition, no olefinic or any other absorptions were observed and therefore the sequential purity of the copolymer is very high. The average molecular weight of the copolymer as determined by gel-permeation chromatography was $7 \times 10^{4}$.

Similar results were obtained for the other copolymers.

\section{Comparison of Periodic and Random Copolymers}

In order to discuss the influence of sequence regularity on the physical properties of copolymers, a random $2: 1$ ethylene-MCA copolymer was prepared. Since ethylene and MCA do not copolymerize to give a high molecular weight product, a random butadiene-MCA copolymer was hydrogenated.

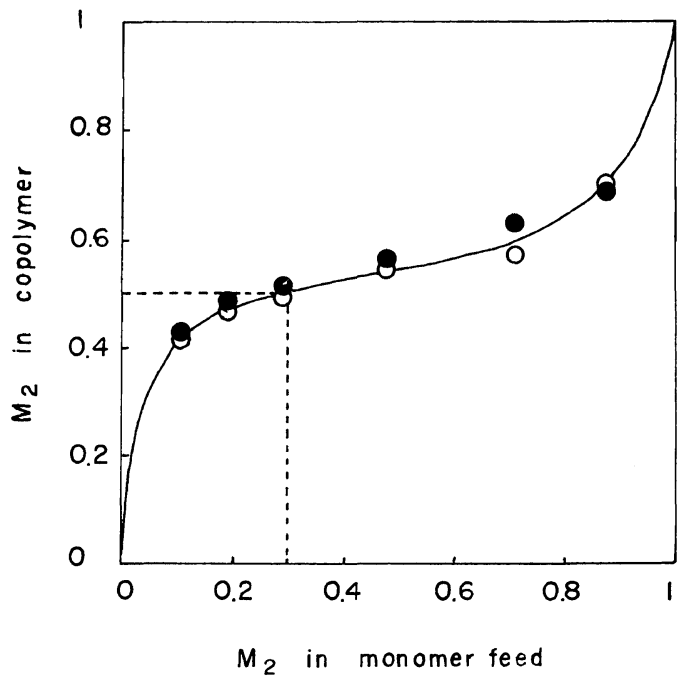

Figure 4. Monomer feed-copolymer composition relationship for the copolymerization of butadiene and MCA with $\alpha, \alpha^{\prime}$-azobisisobutyronitrile at $30^{\circ} \mathrm{C}$. by $\mathrm{C} \%$, $\bigcirc$ by ${ }^{1} \mathrm{H}$ NMR.

Figure 4 shows the monomer feed-copolymer composition relationship for the copolymerization of butadiene and MCA with $\alpha, \alpha^{\prime}$-azobisisobutyronitrile at $30^{\circ} \mathrm{C}$ in sealed tubes. The monomer reactivity ratios are $r_{\mathrm{Bd}}=0.045$, and $r_{\mathrm{MCA}}=0.195$. This figure shows that a $1: 1$ butadiene-MCA copolymer will be obtained at a low conversion by feeding butadiene and MCA in a 0.7:0.3 molar ratio. The copolymer thus obtained was hydrogenated to give a copolymer containing $2: 1$ ethylene- 


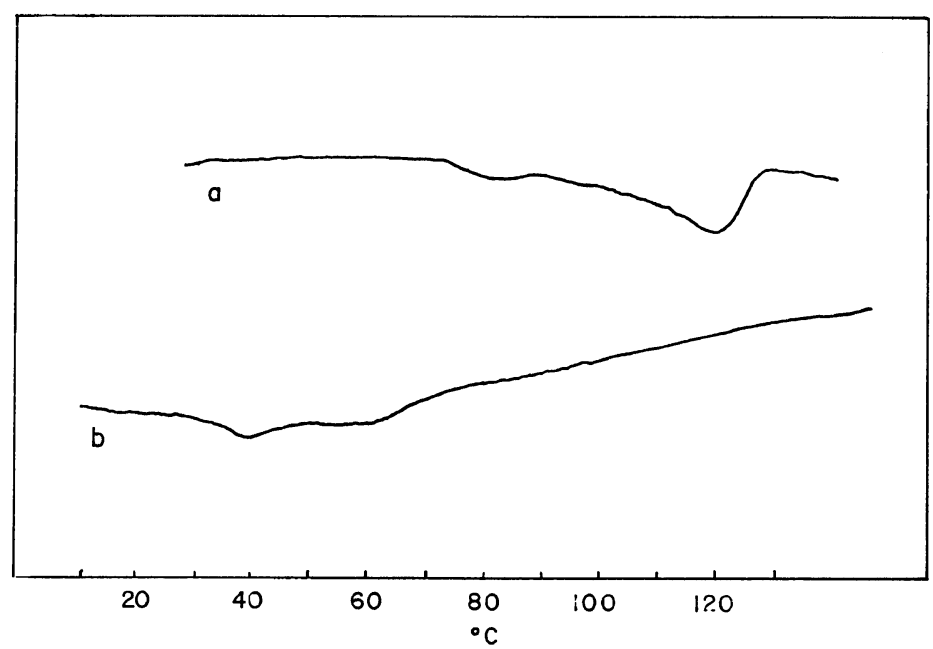

Figure 5. Differential scanning calorimetry of (a) the periodic and (b) the "random" $2: 1$ ethylene-MCA copolymer.

MCA units with a "random" sequence distribution. Since the product of the monomer reactivity ratios is fairly small, this "random" copolymer contains a high fraction of ethylene-ethylene-MCA sequences and, in a strict sense, is not a random copolymer. Calculation using the equation,

$$
\begin{aligned}
f_{\mathrm{Bd}-\mathrm{MCA}}= & 2 /\left(2+r_{\mathrm{Bd}}[\mathrm{Bd}] /[\mathrm{MCA}]\right. \\
& \left.+r_{\mathrm{MCA}}[\mathrm{MCA}] /[\mathrm{Bd}]\right)
\end{aligned}
$$

where $f_{\mathrm{Bd}-\mathrm{MCA}}$ denotes a fraction of the butadieneMCA sequences and therefore the fraction of ethylene-ethylene-MCA sequences following hydrogenation and $[\mathrm{Bd}] /[\mathrm{MCA}]$ denotes the feed ratio of the monomers, shows that the fraction of ethylene-ethylene-MCA sequences is as high as $91 \%$. But as shown below, the physical properties of the periodic and "random" copolymers differ distinctly. A very weak absorption due to a small fraction of 1,2-butadiene units was found in the NMR spectrum at $0.5 \mathrm{ppm}$ higher than that of $-\mathrm{CH}=\mathrm{CH}$ - of the "random" unsaturated copolymer, though a quantitative estimation was not possible.

Figure 5 shows the results of differential scanning calorimetry of the periodic and "random" $2: 1$ ethylene-MCA copolymers. The periodic copolymer shows a melting peak at $120^{\circ} \mathrm{C}$ and a glasstransition peak at $76^{\circ} \mathrm{C}$ while the "random" copolymer shows no melting peak and only a glass-transition peak at $37^{\circ} \mathrm{C}$. Essentially the

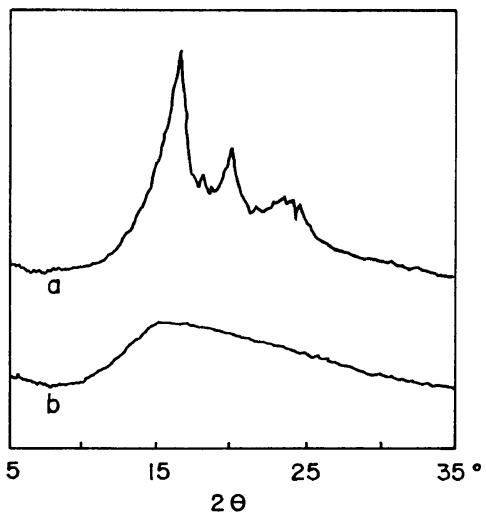

Figure 6. X-Ray diffraction patterns of (a) the periodic and (b) the "random" 2:1 ethylene-MMA copolymer.

same was observed for the periodic and the "random" 2:1 ethylene-MMA copolymers.

The X-ray diffraction patterns in Figure 6 demonstrate that the periodic copolymer is partially crystalline and the "random" copolymer to be amorphous in the case of $2: 1$ ethyleneMMA copolymers.

Tensile Properties of Various Ethylene-EthyleneAcrylic Copolymers

Table I gives the tensile properties of ethyleneethylene-methyl acrylate and -MCA copolymers along with those of the MMA copolymer in the previous paper. The methyl acrylate copolymer, 


\section{K. Yokota, T. Kougo, and T. Hirabayashi}

Table I. Properties of ethylene-ethylene-acrylate copolymers

\begin{tabular}{|c|c|c|c|c|c|c|c|}
\hline \multirow{2}{*}{ Copolymer } & \multirow{2}{*}{$\frac{d^{20}}{\mathrm{~g} \mathrm{~cm}^{-3}}$} & \multirow{2}{*}{$\frac{T_{\mathrm{m}}}{{ }^{\circ} \mathrm{C}}$} & \multirow{2}{*}{$\frac{T_{\mathrm{g}}}{{ }^{\circ} \mathrm{C}}$} & \multirow{2}{*}{$\begin{array}{l}\text { Young's } \\
\text { modulus } \\
\mathrm{kg} \mathrm{cm}^{-2}\end{array}$} & \multirow{2}{*}{$\begin{array}{c}\begin{array}{c}\text { Stress at } \\
\text { yield }\end{array} \\
\mathrm{kg} \mathrm{cm}^{-2}\end{array}$} & \multirow{2}{*}{$\begin{array}{c}\begin{array}{c}\text { Stress at } \\
\text { break }\end{array} \\
\mathrm{kg} \mathrm{cm}^{-2}\end{array}$} & \multirow{2}{*}{$\begin{array}{c}\begin{array}{c}\text { Elongation } \\
\text { at break }\end{array} \\
\frac{\%}{\%}\end{array}$} \\
\hline & & & & & & & \\
\hline $\mathrm{E}^{\mathrm{a}}-\mathrm{E}-\mathrm{MMA}$ & 1.052 & 90 & 45 & $1 \times 10^{3}$ & $1 \times 10^{2}$ & $3 \times 10^{2}$ & 300 \\
\hline $\mathrm{E}-\mathrm{E}-\mathrm{MA}^{\mathrm{b}}$ & 1.057 & $40^{\mathrm{c}}$ & -30 & $1 \times 10^{2}$ & $2 \times 10^{1}$ & $1 \times 10^{2}$ & 600 \\
\hline E-E-MCA & 1.214 & 120 & 76 & $3 \times 10^{3}$ & $2 \times 10^{2}$ & $2 \times 10^{2}$ & 100 \\
\hline $\begin{array}{l}\mathrm{E}_{2}-\mathrm{MCA} \\
\text { (Random) }\end{array}$ & 1.194 & - & 37 & $3 \times 10^{2}$ & $5 \times 10^{1}$ & $2 \times 10^{2}$ & 400 \\
\hline \multicolumn{8}{|c|}{$\begin{array}{l}\text { a E, ethylene. } \\
\text { b MA, methyl acrylate. } \\
\text { c Three peaks around } 40^{\circ} \mathrm{C} \text {. }\end{array}$} \\
\hline \multirow{2}{*}{ Copolymer } & $d^{20}$ & $T_{\mathrm{m}}$ & $T_{\mathrm{g}}$ & $\begin{array}{l}\text { Young's } \\
\text { modulus }\end{array}$ & $\begin{array}{l}\text { Stress at } \\
\text { yield }\end{array}$ & $\begin{array}{c}\text { Stress at } \\
\text { break }\end{array}$ & $\begin{array}{l}\text { Elongation } \\
\text { at break }\end{array}$ \\
\hline & $\mathrm{g} \mathrm{cm}^{-3}$ & ${ }^{\circ} \mathrm{C}$ & ${ }^{\circ} \mathrm{C}$ & $\mathrm{kgcm}^{-2}$ & $\mathrm{~kg} \mathrm{~cm}^{-2}$ & $\mathrm{~kg} \mathrm{~cm}^{-2}$ & $\%$ \\
\hline $\begin{array}{l}\mathrm{E}^{a}-\mathrm{E}-\mathrm{Ethyl} \\
\text { methacrylate }\end{array}$ & 1.005 & - & -32 & $1 \times 10^{1}$ & 3.5 & 2 & 500 \\
\hline $\begin{array}{c}\text { E-E--Isopropyl } \\
\text { methacrylate }\end{array}$ & 0.982 & - & -26 & $1 \times 10^{1}$ & 3.5 & 3 & 1100 \\
\hline $\begin{array}{l}\text { E-E-Phenyl } \\
\text { methacrylate }\end{array}$ & 1.105 & - & +14 & $1.5 \times 10^{1}$ & 5 & $5 \times 10^{1}$ & 600 \\
\hline $\begin{array}{l}\text { E-E-Benzyl } \\
\text { methacrylate }\end{array}$ & 1.099 & +47 & $?$ & $2.5 \times 10^{2}$ & $3 \times 10^{1}$ & $1.5 \times 10^{2}$ & 500 \\
\hline
\end{tabular}

a E, ethylene.

where $\alpha$-methyl in the MMA copolymers was substituted with hydrogen, shows lower $T_{\mathrm{m}}$ and $T_{\mathrm{g}}$ at 40 and $-30^{\circ} \mathrm{C}$, respectively, and is softer and more extensible than the MMA copolymer. The chlorine substitution causes both $T_{\mathrm{m}}$ and $T_{\mathrm{g}}$ to rise and makes the MCA copolymer somewhat harder and more brittle. Table I also shows that the periodic MCA copolymer is harder and less extensible than the "random" copolymer.

Table II shows $T_{\mathrm{m}}, T_{\mathrm{g}}$ and the tensile properties of the four ethylene-ethylene-methacrylate copolymers. Only the benzyl copolymer shows $T_{\mathrm{m}}$ and hence is partially crystalline. The other copolymers are amorphous and are characterized as very soft and highly extensible.

Acknowledgement. The authors wish to thank Mrs. M. Aoyama for her assistance in the preparation of this manuscript.

\section{REFERENCES}

1. S. Iwatsuki and Y. Yamashita, in "Progress in Polymer Science Japan," Vol. 2, M. Imoto and S. Onogi, Ed., Kodansha, Tokyo, 1971, pp $1-48$

2. J. Furukawa, J. Polym. Sci., Polym. Symp., No. 51, 105 (1975).

3. H. Hirai, J. Polym. Sci., Macromol. Rev., 11, 47 (1976).

4. H. L. Hsieh, J. Macromol. Sci., Chem., A7, 1525 (1973).

5. T. Saegusa, Makromol. Chem., Suppl., 3, 157 (1979).

6. K. Yokota and T. Hirabayashi, Polym. J., 13, 813 (1981).

7. K. Yokota and T. Hirabayashi, Macromolecules, 14, 1613 (1981).

8. K. Yokota, M. Kani, and Y. Ishii, J. Polym. Sci., A1, 6, 1325 (1968).

9. T. Hirabayashi and K. Yokota, J. Polym. Sci., Polym. Chem. Ed., 14, 45 (1976).

10. L. A. Mango and R. W. Lenz, Makromol. Chem., 163, 13 (1973). 